\title{
Vulnerabilidade feminina para infecções sexualmente transmissíveis durante visita íntima
}

\author{
Female vulnerability to update sexuality during intimate visitation \\ Vulnerabilidad femenina para actualizar la sexualidad durante la visita íntima
}

Laynara Maria das Graças Alves Lobo ${ }^{1}$, Mayron Morais Almeida², Thiago Sampaio dos Santos², Wygor Bruno e Silva Moraes², Darlyson Emanuel Sena de Freitas², Francisco Braz Milanez Oliveira ${ }^{3},{ }^{4 *}$.

\section{RESUMO}

Objetivo: Analisar a percepção de mulheres acerca das vulnerabilidades para infecções sexualmente transmissíveis (IST) durante a visita Íntima em unidades de um sistema prisional. Método: Trata-se de um estudo qualitativo, descritivo e exploratório, realizado com 29 mulheres, companheiras de homens em situação de privação de liberdade. A produção dos dados de deu mediante entrevista realizada durante o ano de 2016. A análise dos dados ocorreu por meio do software Iramutec. A pesquisa foi aprovada sob o no CAAE: 56476715.3.0000.8007. Resultados: A idade dos participantes variou entre 18 a 46 anos; a cor da pele autor referida parda foi predominante $(65,5 \%) ; 10,3 \%$ dos participantes referiram já terem adquirido alguma infecção sexualmente transmissível. Associou-se à prevenção e a proteção às infecções sexualmente transmissíveis ao uso do preservativo, sendo que a percepção da vulnerabilidade está ligada à confiança no parceiro. Conclusão: não houve percepção de vulnerabilidade para infecções sexualmente transmissíveis por parte das mulheres participantes do estudo, evidenciando a necessidade da promoção da educação sexual dessas mulheres e seus companheiros no contexto prisional. O estudo foi essencial para entender os conceitos de vulnerabilidade sob a percepção de uma população de risco, sendo que outros estudos são necessários para aprofundamento do tema.

Palavras-chave: Percepção, Mulheres, Vulnerabilidade em saúde, Prisioneiros.

\begin{abstract}
Objective: To analyze the perception of women about vulnerabilities for sexually transmitted infections (STIs) during the Intimate visit in units of a prison system. Method: This is a qualitative, descriptive and exploratory study carried out with 29 women, partners of men in situations of deprivation of liberty. The production of data from gave an interview conducted during the year 2016. Data analysis was performed using Iramutec software. The research was approved under CAAE number: 56476715.3.0000.8007. Results: The participants' ages ranged from 18 to 46 years; the self-reported brown skin color was predominant (65.5\%); $10.3 \%$ of participants reported having acquired some sexually transmitted infection. It has been associated with the prevention and protection of sexually transmitted infections from condom use, and the perception of vulnerability is linked to trust in the partner. Conclusion: There was no perception of vulnerability to sexually transmitted infections among the women participating in the study, evidencing the need to promote the sexual education of these women and their partners in the prison context. The study was essential to understand the concepts of vulnerability under the perception of a population at risk, and other studies are necessary to deepen the theme.
\end{abstract}

Key words: Perception, Women, Health Vulnerability, Prisoners.

${ }^{1}$ Enfermeira especialista em oncologia e saúde pública. Mestranda em Enfermagem pela Universidade Federal do Piauí/UFPI. Teresina (PI).

2 Enfermeiro graduado pela Faculdade de Ciências e Tecnologia do Maranhão (FACEMA). Caxias (MA).

${ }^{3}$ Docente do Curso de Enfermagem e Coordenador de Pesquisa e Pós-graduação do Centro Universitário de Ciências e Tecnologia do Maranhão - UNIFACEMA. Caxias (MA). Brasil. E-mail: braz_cm@hotmail.com

${ }^{4}$ Instituto Oswaldo Cruz (IOC). Programa de pós-graduação em Medicina Tropical -Fiocruz Teresina (PI). 


\section{RESUMEN}

Objetivo: Analizar la percepción de las mujeres sobre las vulnerabilidades para las infecciones de transmisión sexual (IST) durante la visita íntima en unidades de un sistema penitenciario. Método: Se trata de un estudio cualitativo, descriptivo y exploratorio, realizado con 29 mujeres, compañeras de hombres en situación de privación de libertad. La producción de los datos de dio mediante entrevista realizada durante el año 2016. El análisis de los datos ocurrió por medio del software Iramutec. La investigación fue aprobada bajo el número CAAE: 56476715.3.0000.8007. Resultados: La edad de los participantes varía entre 18 a 46 años; el color de la piel autorreferida parda fue predominante (65,5\%); El 10,3\% de los participantes mencionó haber adquirido alguna infección de transmisión sexual. Se asoció a la prevención y la protección a las infecciones de transmisión sexual al uso del preservativo, siendo que la percepción de la vulnerabilidad está ligada a la confianza en el socio. Conclusión: no hubo percepción de vulnerabilidad para infecciones sexualmente transmisibles por parte de las mujeres participantes del estudio, evidenciando la necesidad de la promoción de la educación sexual de esas mujeres y sus compañeros en el contexto penitenciario. El estudio fue esencial para entender los conceptos de vulnerabilidad bajo la percepción de una población de riesgo, mientras que otros estudios son necesarios para profundizar el tema.

Palabras clave: Percepción, Mujeres, Vulnerabilidad en salud, Prisioneros.

\section{INTRODUÇÃO}

O conceito de vulnerabilidade na área da Saúde Pública teve início na década de 1990 associado a epidemia de HIV/AIDS, na qual foram realizados desenhos de intervenção norteados por enfoques da atenção integral e processos de mobilização social fundamentados nos Direitos Humanos. Contudo, o conceito de vulnerabilidade se apresenta como um campo ainda a ser explorado; passível de elaboração conceitual capaz de alcançar um amplo e heterogêneo universo de reflexões e práticas (MALAGON e DINA, 2015).

No campo da epidemiologia, a vulnerabilidade pode ser compreendida como um movimento que considera a chance de exposição das pessoas ao adoecimento, como resultante de um conjunto de aspectos individuais, coletivos, contextuais que acarretam maior suscetibilidade à infecção e ao adoecimento (ROSA et al., 2012).

A privação de liberdade leva pessoas encarceradas a condições de limitação de espaço, de organização social e mental, que predispõe comportamentos de risco para múltiplas infecções transmitidas de pessoa a pessoa, como por exemplo, as infecções sexualmente transmissíveis (IST), (ROSA et al., 2012).

Estima-se que cerca de 350 mil pessoas estão encarceradas no Brasil, a maioria são jovens: média de 28 anos para os homens e 31 anos para as mulheres, sendo elevado o número de presos que tinham história de passagem pelo Juizado da Infância e da Juventude. As mulheres encarceradas possuem, na grande maioria, baixo nível socioeconômico e educacional, alto índice de IST, com história de uso de alguma droga ilícita e álcool, e não utilização da camisinha durante as relações sexuais (ALQUIMIM, 2014).

Considera-se as pessoas privadas de liberdade como grupo de risco elevado para as ISTs. Muitos usam drogas lícitas e ilícitas, algumas com auxílio de seringas que podem estar contaminadas, e praticam sexo sem preservativos (SALAUDEEN et al., 2014; MORRIS et al., 2014). Apresentam ainda vulnerabilidades individuais e sociais, como precariedade de acesso aos serviços de saúde, baixa escolaridade, grande mobilidade geográfica, e barreiras relacionadas a gênero e estigmas sociais (FAGEEH, 2014; MATOS et al., 2013).

A precária situação observada no sistema carcerário é confirmada pelo acentuado número de comorbidades existentes na população carcerária as quais apresentam suscetibilidade às doenças sexualmente transmissíveis (DST). Este contexto nos remete à violação de seus direitos sexuais e reprodutivos sugerindo importantes questões a serem discutidas na saúde pública (ALQUIMIM, 2014).

Dentro das unidades prisionais os prisioneiros estão suscetíveis a várias doenças infectocontagiosas, dentre elas, as mais comuns são as doenças do aparelho respiratório, como a tuberculose e a pneumonia. Também é alto o índice da hepatite e de infecções sexualmente transmissíveis (ISTs), em geral a Aids por excelência (LOPES e OLIVEIRA, 2014). 
A lei de execução penal assegura a pessoas privada de liberdade o direito da visita do cônjuge, da companheira, parentes e amigos em dias determinados, porém, somente em 1999 o Conselho Nacional de Política Criminal e Penitenciaria (CNPCP) recomendou aos departamentos penitenciários estaduais ou órgãos congêneres, que fossem assegurados a visita íntima. Portanto, a visita íntima é direito abrigado constitucionalmente, face à interpretação de que a sexualidade é dimensão da vida de todas pessoas (Matos et al., 2013).

Frente à problemática, têm-se por questões norteadoras: Qual a percepção feminina quanto à vulnerabilidade para infecções sexualmente transmissíveis durante a visita íntima em uma unidade prisional? Para responder a tal inquietação, o presente estudo tem por objetivo analisar a percepção de mulheres acerca das vulnerabilidades para infecções sexualmente transmissíveis (IST) durante a visita Íntima em unidades de um sistema prisional.

\section{MÉTODOS}

Trata-se de um estudo descritivo, exploratório, com abordagem qualitativa, realizada em uma Central de Custódia de Presos Judiciais (CCPJ) masculina, cuja finalidade é abrigar presos em regime provisório, semiaberto e fechado, localizada no município de Caxias, situado ao leste do estado do Maranhão, Nordeste do Brasil. A referida unidade tem capacidade para 80 detentos, porém, sua lotação atual é de 158 pessoas, sendo 84 provisórios e 74 sentenciados.

As visitas para coletas de dados ocorreram duas vezes semanais, as quartas e sextas feiras no período das $9 \mathrm{~h}$ da manhã as $17 \mathrm{~h}$. A sistemática adotada pela CCPJ foi estabelecida por ordem de chegada das mulheres, sendo permitido somente a permanência de 3 visitantes simultaneamente em cada cela. Para adentrar na Unidade era necessário a apresentação da carteira de identidade para realização de um cadastro diário. Após o cadastro as visitantes eram direcionadas a uma sala privativa com a presença de duas funcionárias da unidade para realização de revista íntima nas mesmas. Segundo informações colhidas com as mulheres cônjuges, a visita intima é realizada na própria cela, sem um espaço pré-definido, sendo utilizado um lençol para divisão de espaços, denominado "empanada".

O estudo foi composto por 29 mulheres cônjuges das pessoas privadas de liberdade com idade igual ou maior a 18 anos, em condições mentais para participar do estudo, que estavam no local para visita na época da coleta de dados, e que assentiram em participar do estudo. Foram excluídas, mulheres com idade inferior a 18 anos e as que não eram cônjuges de internos.

Aplicou-se um questionário semiestruturado contendo perguntas fechadas. As questões referentes a caracterização sociodemográfica abordavam aspectos quanto: idade, raça, escolaridade, tipo e condições de moradia, trabalho, renda e religião. Quanto aos hábitos de vida, abordou-se o consumo de álcool e drogas, uso de tatuagens, compartilhamento de perfurocortantes, imunização, realização de testes para ist's, uso de preservativos durante a relação, história de infecções sexualmente transmissíveis, números de parceiros e prática sexual. Nas perguntas abertas questionou-se o conhecimento das participantes acerca das ist's, forma de transmissão e prevenção, orientações quanto a educação em saúde, e o autoconhecimento das mesmas quanto a exposição durante a visita intima. Transcreveu-se os dados coletados nas entrevistas para o software Iramutec (Interface de R pour lês Analyses Multidimensionnelles de Textes et de Questionnaires). Trata-se de um programa que se ancora no software $\mathrm{R}$ e permite diferentes formas de análises estatísticas sobre corpus textuais e tabelas de indivíduos por palavras. O Iramuteq viabiliza diferentes tipos de análises, das mais simples às multivariadas, como a Classificação Hierárquica Descendente, e organiza a distribuição do dicionário para que fique de fácil compreensão e clara visibilidade.

Neste estudo, para o processamento de dados utilizou-se o dendograma da Classificação Hierárquica Descendente e a nuvem de palavras. Assim, as palavras são agrupadas e organizadas graficamente de acordo com a sua frequência, o que possibilita facilmente a sua identificação, a partir de um único arquivo, denominado corpus, que reúne os textos originados pelas entrevistas. Assim, cada entrevista caracterizou um texto, e o conjunto desses textos constituiu o corpus de análise desta pesquisa.

REAS/EJCH | Vol. 11 (8) | e653 | DOI: https://doi.org/10.25248/reas.e653.2019 Página 3 de 12 
Por se tratar de uma pesquisa com seres humanos o presente trabalho foi submetido para avaliação num Comitê de Ética em Pesquisa, sendo aprovado sob o № de CAAE: 56476715.3.0000.8007, conforme preconiza a Resolução № 466/2012 do CNS/MS.

\section{RESULTADOS E DISCUSSÃO}

Foram inclusos neste estudo 29 participantes do sexo feminino, destes, a média de idade variou de 18 a 46 anos, cor da pele predominante parda (65,5\%). No que se refere ao grau de instrução, da amostra total, $62 \%$ possuíam o ensino fundamental apenas. Em relação a maternidade $86,2 \%$ da amostra relataram ser mães, das quais $52 \%$ tinham entre três ou mais filhos. A fonte de renda, vem do trabalho informal $(48,2 \%)$ e individual $(65,5 \%)$. Quanto à imunização para hepatite B, 72,4\% já foram imunizadas, $89,6 \%$ já fizeram triagem sorológica para HIV/AIDS, Sífilis e Hepatite B. Nesta amostra, 58,6\% referiram que não utilizavam preservativo durante as relações sexuais, 10,3\% já adquiriram alguma infecção sexualmente transmissível, $65,5 \%$ mulheres realizavam somente por via vaginal (Tabela 1).

Tabela 1 - Caracterização das participantes do estudo quanto às variáveis socioeconômicas, demográficas, hábitos e estilo de vida. Caxias (MA), Brasil, 2018. (N=29).

\begin{tabular}{|c|c|c|c|}
\hline VARIÁVEIS & & $\mathrm{N}^{\circ}$ & $\%$ \\
\hline \multirow[t]{4}{*}{ Idade } & 18 a 24 & 11 & $37,9 \%$ \\
\hline & 25 a 31 & 9 & $31 \%$ \\
\hline & 32 a 38 & 8 & $27,5 \%$ \\
\hline & 39 a 46 & 1 & $3,4 \%$ \\
\hline \multirow[t]{4}{*}{ Raça/Cor } & Branca & 2 & $6,8 \%$ \\
\hline & Negra & 5 & $17,2 \%$ \\
\hline & Parda & 19 & $65,5 \%$ \\
\hline & Amarela & 3 & $10,3 \%$ \\
\hline \multirow[t]{3}{*}{ Escolaridade } & Ensino fundamental & 18 & $62 \%$ \\
\hline & Ensino médio & 10 & $34,4 \%$ \\
\hline & Ensino superior & 1 & $3,4 \%$ \\
\hline \multirow[t]{2}{*}{ Possui Filhos } & Sim & 25 & $86,2 \%$ \\
\hline & Não & 4 & $13,7 \%$ \\
\hline \multirow[t]{3}{*}{ Fonte de renda } & Trabalho formal & 6 & $20,6 \%$ \\
\hline & Trabalho informal & 14 & $48,2 \%$ \\
\hline & Sem renda & 9 & $31 \%$ \\
\hline \multirow[t]{2}{*}{ Uso de droga } & Sim & 2 & $6,8 \%$ \\
\hline & Não & 27 & $93,1 \%$ \\
\hline \multirow{2}{*}{$\begin{array}{l}\text { Compartilhamento de material perfuro } \\
\text { cortante }\end{array}$} & Sim & 21 & $72,4 \%$ \\
\hline & Não & 8 & $27,5 \%$ \\
\hline \multirow[t]{3}{*}{ Imunização contra Hepatite B } & Sim & 21 & $72,4 \%$ \\
\hline & Não & 5 & $17,3 \%$ \\
\hline & Não sei & 3 & $10,3 \%$ \\
\hline \multirow[t]{3}{*}{ Realizou Teste HIV, sífilis e Hepatite B } & Sim & 26 & $89,6 \%$ \\
\hline & Não & 2 & $6,8 \%$ \\
\hline & Não sei & 1 & $3,4 \%$ \\
\hline \multirow[t]{3}{*}{ Uso de Preservativo } & Sim & 17 & $58,6 \%$ \\
\hline & Não & 6 & $20,6 \%$ \\
\hline & As vezes & 6 & $20,6 \%$ \\
\hline \multirow[t]{2}{*}{ História de IST } & Sim & 3 & $10,3 \%$ \\
\hline & Não & 26 & $89,6 \%$ \\
\hline \multirow[t]{3}{*}{ Prática sexual } & Vaginal & 19 & $65,5 \%$ \\
\hline & Vaginal e oral & 7 & $24,1 \%$ \\
\hline & Vaginal, oral e anal & 3 & $10,3 \%$ \\
\hline
\end{tabular}

Fonte: Dados da pesquisa, 2018. 
O corpus textual analisado é composto de 29 unidades de contexto inicial (UCI) dos quais se obtiveram 90 segmentos de texto ou unidades de contexto elementar (UCE). O Iramutec reconheceu a separação do corpus em 54 unidades de texto elementares, com aproveitamento de $60 \%$ dele. A Classificação Hierárquica Descendente (CHD), identificou cinco classes semânticas no material analisado e a associação dessas classes às variáveis fixas do estudo. O corpus da pesquisa primeiramente foi dividido em dois sub-corpus, um desses sub-corpus originou duas classes 4 e 1 . O segundo sub-corpus foi dividido em dois, dando origem a classe 5, que engloba mais duas classes, 3 e 2, conforme mostra a Figura 1.

Figura 1 - Dendograma da Classificação Hierárquica Descendente por classes e unidades de contexto elementar sobre a percepção feminina quanto à vulnerabilidade para infecções sexualmente transmissíveis durante a visita íntima em uma unidade prisional. Caxias (MA), Brasil, 2018.

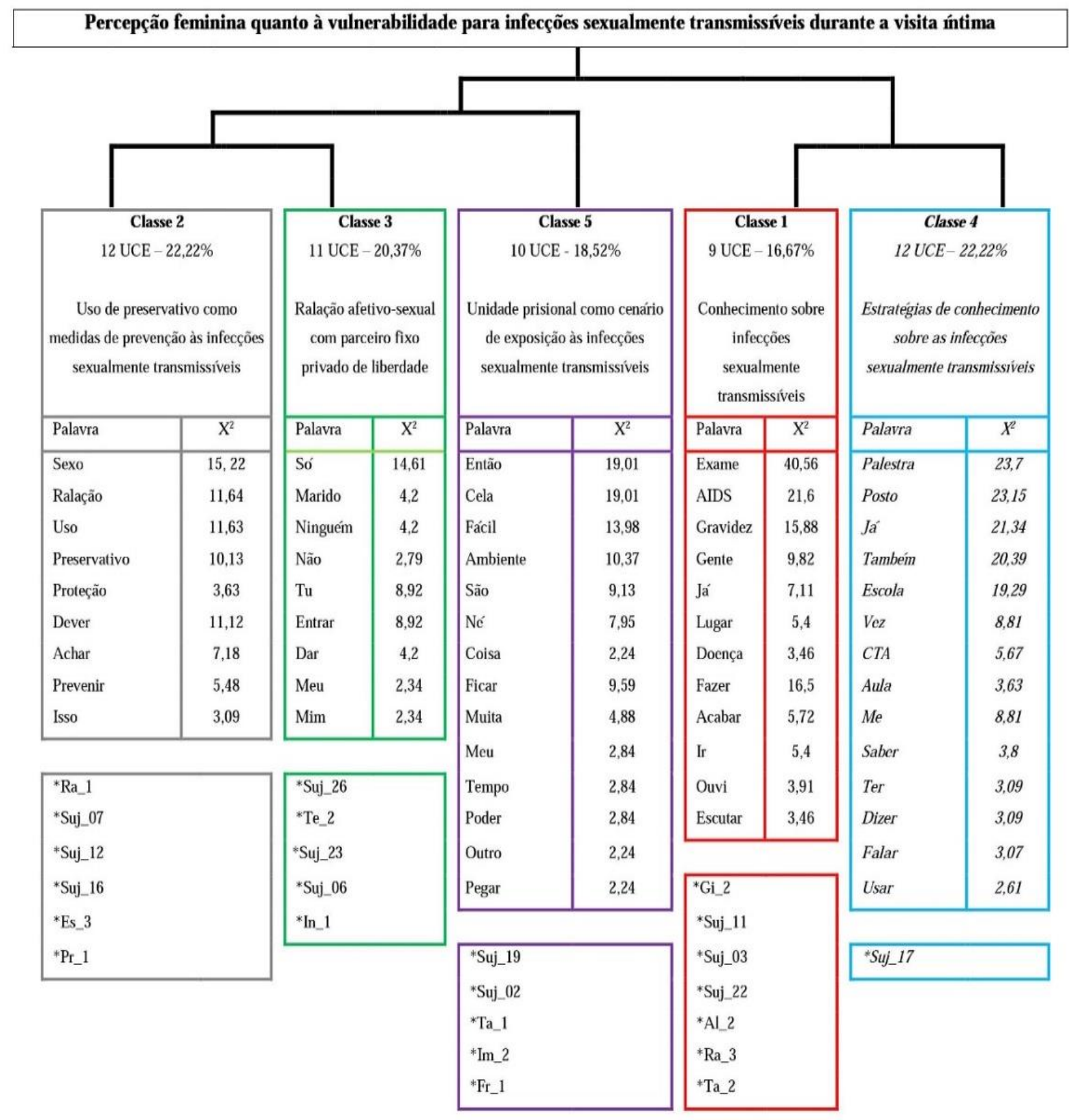

Fonte: Dados da pesquisa, 2018. 


\section{Classe 2 - Uso de preservativo como medida de prevenção às (IST).}

A classe 2 apresenta 12 UCE de 54 , respondendo por $22.22 \%$ do corpus estando associada diretamente à classe 3. Os vocábulos que mais surgem na análise destes segmentos de textos são: sexo, relação, uso, preservativo, proteção, dever achar, prevenir, isso, sendo eles identificados no conteúdo das entrevistas das participantes 07, 12 e 16 por ordem de significância. Mulheres que contribuíram significativamente para compor esta classe eram brancas, com grau de escolaridade de nível médio e que faziam uso do preservativo durante a relação sexual.

Pela extração das falas o estudo revela que grande parte da amostra associa a prevenção e a proteção às infecções sexualmente transmissíveis ao uso do preservativo. A maioria das mulheres que compõe o estudo $(58,6 \%)$ relatou usar o preservativo durante o ato sexual, a adesão do método, segundo as depoentes, se deu por terem escutado alguma vez na vida que é há a necessidade do uso e por conhecerem que o não uso pode ocasionar doenças. Quanto ao uso do preservativo:

"O preservativo é o mais seguro, então eu uso sim (Suj_16). Tem que usar, né!? Porque senão já pego alguma coisa, doença (Suj_20). A gente usa, tem que usar, né!? (Suj_21). Sim sempre, eu uso porque a gente escuta dizer que a gente tem que usar toda vez (Suj_24)."

A prática do uso do preservativo está ligada a algo cotidiano, que acontece mais por um ouvi falar que previne doenças do que por saber de fato que existem doenças e que essas podem ser prevenidas (OLIVEIRA e SANTOS, 2012), isso porque quando essas mulheres foram questionadas quanto as possíveis doenças que podem ser prevenidas não souberam responder.

Embora haja o conhecimento acerca da importância do preservativo, notou-se a falta de informação quanto ao modo de prevenção, sugerindo assim uma maior exposição às mulheres (RODRIGUES et al., 2012). Quando indagadas às formas de prevenção, as mesmas relatam:

"A camisinha que previne que eu saiba é só isso mesmo, se tem outro jeito eu ainda não vi (suj_25). Acho que e usando a camisinha pra prevenir, né!? Eu uso sim, é o certo, pra não ficar doente depois (suj_27). Se for a mesma coisa que estou pensando ser, é transmitido através da relação sexual de pessoa pra pessoa, quando tem o ato sem a proteção. Pode ser prevenida com o uso do preservativo, por isso eu sempre uso durante a relação (suj_03)."

Percebe-se que o preservativo é compreendido como uma das formas mais concretas de prevenção contra DST/AIDS (MATOS et al., 2013; Moura et al., 2017). Outro estudo corrobora com essa ideia estabelecendo o uso de preservativo como prática reconhecida publicamente como base para prevenções às infecções sexualmente transmissíveis, onde todo e qualquer aconselhamento voltado às ISTs traz esse conteúdo informativo (LIMA et al., 2016).

\section{Classe 3 - Relação afetivo-sexual com parceiro fixo privado de liberdade.}

Esta classe apresenta 11 UCE de 54 , respondendo a $20.37 \%$ do corpus textual, estando associada a classe anterior - 2. As palavras que mais se destacam são: só, marido, ninguém, não, tu, entrar, dar, meu, mim, sendo retiradas predominantemente das falas das participantes 26, 23 e 06 e por mulheres que referiram nunca terem feito testes sorológicos para HIV/AIDS, sífilis e Hepatite B, e que relataram alguma vez na vida terem tido alguma infecção sexualmente transmissível.

Nesta classe as três palavras de maior ocorrência utilizadas pelas mulheres são: só, marido e ninguém. Isso ocorreu porque, embora não sendo a minoria, parte das entrevistadas relatam não usar o preservativo, dessas, uma parcela demonstrou confiança na relação com o parceiro e outra parcela demonstrou confiança na situação em que o parceiro se encontra, tendo em vista que, frente à situação dele não haverá uma terceira pessoa na relação do casal.

O sentimento de desconfiança para com o parceiro também surgiu entre as falas, porém, o uso do preservativo é dispensado por questões de gosto do parceiro privado de liberdade e/ou do casal. Ainda pôdese observar a falta de interesse e pouca importância dada ao método de prevenção, principalmente no 
momento em que a mulher não pode mais engravidar, também é colocada a prática do não uso como algo rotineiro, como mostra as falas das depoentes:

"Não usamos preservativos, antes a gente usava, mas hoje não porque eu fiz laqueadura, aí não
precisa (Suj_04). Não uso. Não, porque meu marido não tem nada, ele já fez exame um tempo
desses e não deu nada, ele fica só comigo e ele está aqui ainda por cima (Suj__05). Não uso, é
muito difícil, ele é meu marido, então não tem perigo, ele não fica com mais ninguém também
(Suj_7). Não, ele está preso e aí ele não tem ninguém pra ele, não é possível que ele ainda me
passe alguma coisa (Suj_09). Com meu marido eu não uso não; não sei se ele só fica comigo,
vai saber né, não sei se ele tem outra visita ai que vem no dia que eu não venho, porque aqui a
gente só pode entrar um dia, que aqui é por ala que tem os presos, eu venho na quinta, vai que
vem outra aí na quarta-feira ou na sexta-feira e eu não estou sabendo; vai saber né, tu sabe
como é homem, tem jeito pra tudo nessa vida (Suj_23). Nunca. Não usamos, e péssimo usar;
ele está preso aqui, não está com mais ninguém (Suj_10). Não uso, meu marido não gosta, ele
diz que incomoda (Suj_15). Só às vezes, não gosto, e meu marido está com caroço no pênis, o
médico disse que ainda e sífilis no sangue, eu mesma já fiz tratamento aí não tem mais (Suj_17)."

Destaca-se o efeito da não proteção das mulheres casadas ou daquelas que vivem em união estável, as tem colocado em situações de vulnerabilidade em relação às doenças sexualmente transmissíveis, principalmente ao HIV/AIDS, em decorrência do comportamento sexual desprotegido, creditando aos seus parceiros confiança (LIMA et al., 2016).

Em muitos casos não existem a preocupação com o uso do preservativo durante as relações sexuais, tampouco, preocupação com as IST, isso é atribuído a códigos morais, onde o casamento ou relacionamento estável é apresentado como fator imunizante às doenças. O uso do preservativo traz a ideia de comportamentos que desviam do modelo monogâmico, levando ao surgimento de desconfianças entre os parceiros, ou infidelidade. Esses são sentimentos aos quais as mulheres não estão dispostas a correr, já que por vezes poderia levar à perda do parceiro (SILVA e VARGENS, 2009).

A prática de sexo sem o uso do preservativo, por vezes, está associada a ideia da redução do prazer sexual do casal, impedindo um contato direto entre homem e mulher, provocando assim uma interrupção na interação dos parceiros (MADUREIRA e TRENTINI, 2008).

\section{Classe 5 - unidade prisional como cenário de exposição às infecções sexualmente transmissíveis.}

A classe apresenta 10 UCE de 54 , respondendo a $18.52 \%$ do corpus textual, englobando as duas classes anteriores - 2 e 3. As palavras que mais se destacam são: então, cela, fácil, ambiente, são, né, coisa, ficar, muita, meu, tempo, poder, outro e pegar, sendo retiradas predominantemente das falas das participantes 19 e 02. Mulheres possuíam tatuagens, e que referiram nunca terem se imunizado contra hepatite $B$.

Houve relatos que apresentavam o ambiente prisional como propicio a aquisição de alguma "doença", o que mais pode ser observado nas falas das participantes do estudo é a associação das péssimas condições de higiene do ambiente à vulnerabilidade para adquirir IST, bem como a quantidade de pessoas dividindo um mesmo espaço físico.

"Tem facilidade de pegar, porque são muitas pessoas, e eles devem usar as coisas dos outros, é muito homem junto (Suj_12). O ambiente é propicio, as condições de higiene são ruins, então eu estou vulnerável sim a contrair alguma infecção dessas (Suj_15). É um lugar parado, não é um ambiente legal, e muito lotado, não cheira bem, eles ficam muito perto um do outro; se vem uma mulher de outro que é doente e passa alguma coisa pro dela e o meu fica perto dele pode pegar, então e fácil demais adoecer, fora a sujeira né!? (Suj_19). Acho fácil pegar porque a água daqui é suja, o ambiente é fechado, são mais ou menos 12 presos em cada cela, então é muita gente, não é ventilado dentro (Suj_20). Com certeza é fácil, Oxe, isso aqui é o que mais acontece, aqui é imundo, se tu entrar ali dentro onde eles ficam, que é no pavilhão tu vê como num é, aí pode sim pegar alguma coisa, e o que mais pega aqui, infecção (Suj_26). Com toda certeza 
desse mundo minha filha, porque o negócio aqui e feio demais, aqui e tudo sujo, aí eles ficam aí de qualquer jeito tudo jogado, e ainda eu não uso camisinha toda vez, fica mais fácil de pagar né!? (Suj_29)."

A restrição do espaço e da mobilidade das pessoas privadas de liberdade, são fatores de risco para infecções sexualmente transmissíveis, segundo, oferecendo assim riscos às mulheres cônjuges dessa população, tendo em vista que, houveram relatos de mulheres que afirmaram não usar o preservativo durante a relação sexual (MALAGON e DINA, 2015). Também se entende a cadeia como ambiente propício a contaminações, devido à aglomeração de pessoas e às más condições habitacionais existentes (REIS e BERNARDES, 2011).

Frente a esses achados referentes às condições de confinamento, ressalta-se que a população encarcerada deveria receber uma atenção especial quanto à identificação de fatores de risco, fundamentadas por ações de educação e aconselhamento, que visassem a prevenção de infecções pelas DST/AIDS com objetivo de melhoria das condições de privação da liberdade, uma vez que, essa população está fortemente vulnerável a contrair DST, pois apresentam comportamentos que põem em risco à sua saúde (SOUZA et al., 2013).

A unidade prisional não era vista como cenário de exposição a infecções sexualmente transmissíveis pelas participantes, houve afirmações que sugeriram a não vulnerabilidade, associadas à utilização do preservativo como método de barreira às infecções, como mostra as falas a seguir:

"Eu sempre uso camisinha na hora do sexo, ainda mais aqui dentro, mesmo o lugar sendo esse eu acho que não tô correndo perigo (Suj_14). Penso que aqui não pego, até porque não entro em contato com os outros presos e uso preservativo durante a relação (Suj_16). Acho que não tem perigo não aqui, porque se eu vou tá usando não tem como eu pegar, eu vou tá protegida (Suj_21)."

Verificou-se nas falas a confiança das mulheres como cuidadoras de si, onde as mesmas demonstram cuidados com a prevenção mesmo quando o parceiro é o marido. O "gostar de si" se faz elemento importante para que o sexo seguro aconteça. O cuidado com o corpo assume posição central na prevenção de DST/ AIDS (MATOS et al., 2013).

\section{Classe 1 - Conhecimento sobre infecções sexualmente transmissíveis.}

A classe apresenta 9 UCE de 54, respondendo a 16.67\% do corpus textual, e está diretamente ligada a classe 4. As palavras que mais se destacam são: exame, AIDS, gravidez, gente, já, lugar, doença, fazer, acabar, ir ouvir, escutar, sendo retiradas predominantemente das falas das participantes 11,03 e 22 . Mulheres que não tiveram gravidez indesejada, que relataram não terem sofrido aborto, que se denominaram de cor parda, que não utilizavam álcool e não possuíam tatuagens.

Esta classe mostra o que as mulheres conhecem quanto as IST. Nota-se em alguns relatos há distorces, como por exemplo, formas de contágio inexistentes, e ausência de conhecimento das mulheres.

Fica claro também que o período da gravidez é o momento em que as mulheres passam a ter melhores conhecimentos acerca das IST, pois exige a busca pelos serviços de saúde dentro das unidades de saúde, onde as informações acerca dessa temática são mais centradas, como mostra as falas das depoentes:

"É sei que vai de todas as formas, às vezes é passado pela relação, pelo beijo, se você usar as coisas do outro, tipo o copo, colher, e também tem que usar preservativo (Suj_11). Sei que são doenças que passa na relação, nos vasos sanitários quando várias pessoas usam, alicate é do mesmo jeito (Suj_12). Eu acho que pega pelo beijo, quando a pessoa tem o dente furado, na relação, de todo jeito pega. Acho que não pode prevenir (Suj_22). Não sei dizer o que é, acho que é doença pela relação sexual, né não? Pelo menos eu acho que é; eu acho que só com a 
camisinha que previne, só conheço esse jeito (Suj_26). Pega não usando camisinha, ou beijando, pegando em uma pessoa doente. Acho que usar a camisinha previne (Suj_27). Só namorando, na relação, ah, e também tem umas que passam se a pessoa sentar na cadeira que a outra estava sentada (Suj_29)."

Dados semelhantes foram encontrados em um estudo realizado com mulheres prostitutas na cidade de Goiânia (GO), no que diz respeito a mitos quanto às formas de transmissão das DST/AIDS, ideias remanescentes ao início da epidemia do HIV na década de 80, como por exemplo o compartilhamento de talheres por pessoas infectadas (MATOS et al., 2013).

Com relação a essas informações errôneas e quanto ao grau de conhecimento sobre DST/AIDS, percebese que não são suficientes para que se adote um comportamento protetor, pois a falta de informações básicas contribui substancialmente para aumentar sua vulnerabilidade (REIS e BERNARDES, 2011). As investigações sobre o conhecimento das mulheres quanto as doenças sexualmente transmissíveis são essenciais para criação de medidas e estratégias de prevenção para grupos populacionais estigmatizados (MATOS et al., 2013; SAMPAIO et al., 2011).

\section{Classe 4 - Estratégias de conhecimento sobre as infecções sexualmente transmissíveis (IST)}

Essa classe apresenta 12 UCE de 54, respondendo a 22.22\% do corpus textual, e está diretamente ligada a classe 1. As palavras que mais se destacam são: palestra, posto, já, também, escola, CTA, aula, me, saber, ter, dizer, falar, usar, sendo retiradas predominantemente da fala da participante 17.

A classe anterior mostrou o conhecimento das participantes sobre as IST e em que momento da vida elas adquiriram esse conhecimento. Completando a classe 1 a classe 4 traz onde essas mulheres tiveram aquisição desses conhecimentos. A maior parte delas relata terem obtido informações nos serviços de saúde e Centro de Testagem e Aconselhamento (CTA) no momento em que foram realizar exames do pré-natal, como mostra a seguir a fala das participantes:

"Eu escutei no médico quando fui lá quando eu tava fazendo meu acompanhamento da gravidez, ele que conversou um pouco disso, mas nem me lembro direito (Suj_2). Só ouvi falar no CTA, onde tem que ir pra fazer alguns exames da gravidez, foi onde eu fui mais orientada foi lá (Suj_3). Sempre tem palestra lá no posto de vez em quando e também quando fui fazer exame no CTA, aquele de AIDS, que a gente faz quando ta gestante, só nesses lugares mesmo (Suj_4). Ouvi lá naquele lugar onde a gente vai fazer exame de HIV, só lá (Suj_5). Mesmo na escola, na televisão as vezes e só mesmo (Suj_7). Já ouvi falar lá no CTA, onde faz exame, na escola, mas já tem um tempão, ouvi um pouco lá no posto também, eu vejo muito e aqueles cartaz falando de doença e de AIDS (Suj_10). Na escola durante as aulas, e em palestra, e também em posto de saúde, que eu me lembre foi só (Suj_24). Lá no CTA, faz uns sete anos que fui lá, mas eles explicam umas coisas lá, também já ouvi pela rua, mas é mais difícil, fora isso em mais lugar nenhum (Suj_28)."

Um estudo com presidiários realizado no estado do Piauí entre os meses de agosto a novembro de 2010 constatou que a maioria dos entrevistados recebeu algum tipo de informação sobre DST, sendo as palestras a mais lembrada. As fontes de informações citadas foram: escolas, hospitais, pais, família, palestras, amigos e televisão, o que também pode ser observado nas falas das mulheres (SOUZA et al., 2013).

$\mathrm{Na}$ análise de similitude (Figura 2), a árvore é apresentada com duas categorias interligadas entre si, cada uma com uma palavra central, sendo uma predominante. A conexidade entre as palavras nos auxilia a entender o que cada categoria representa. Na similitude, a categoria que se sobrepõe traz como centro a palavra "não" e diz respeito predominantemente à percepção da mulher quanto a adquirir alguma infecção dentro da unidade prisional, sendo a maioria na pesquisa $(51,72 \%)$. Na categoria menor a palavra central é "já" e está associada ao fato de as mulheres já terem escutado falar nas IST e onde escutaram. 
Figura 2 - Resultados da análise de similitude. Caxias (MA), Brasil, 2018.

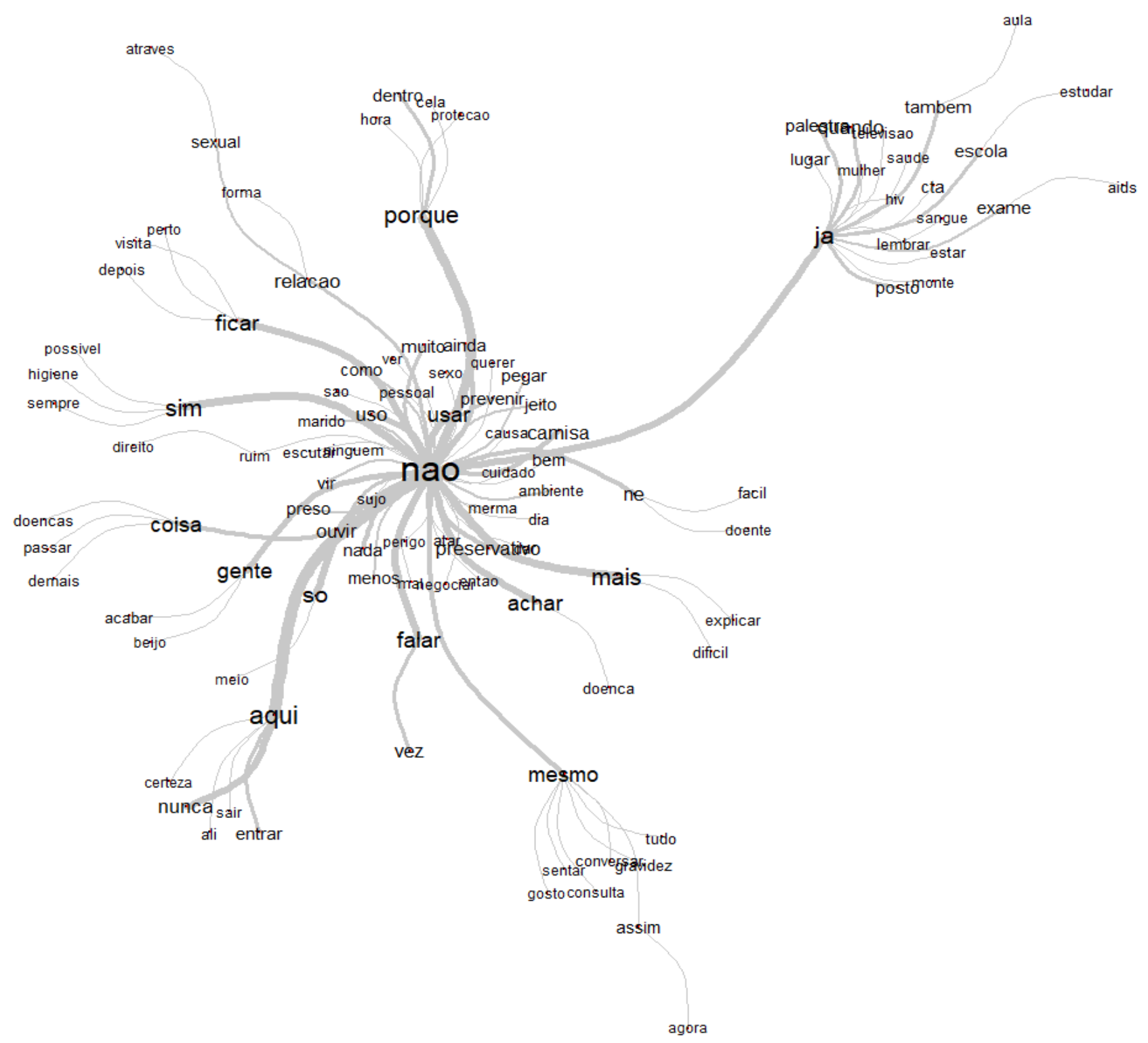

Fonte: Dados da pesquisa, 2018.

A comunicação de massa do tipo televisiva tem contribuído na divulgação de mensagens a respeito dessas questões, porém, a maioria destas mensagens, têm trazido à tona dados mais quantitativos do que qualitativos, ou seja, fala-se muito em números mais do que proporcionado a discussão e reflexões acerca do tema, seria ideal que destacassem mais conhecimentos específicos, garantindo assim a educação em saúde coletiva, atingindo a população de forma mais acelerada e de forma mais eficaz (SOUZA et al., 2013).

A grande maioria das participantes da pesquisa relatou nunca terem tido informações no interior da penitenciária quanto a infecções.

A percepção da vulnerabilidade está ligada à confiança no parceiro, na situação em que o parceiro se encontra e ao uso do preservativo na relação sexual. Grande parte das mulheres continua não se percebendo vulnerável às DST/AIDS ou tem consciência da importância e não se protege. Estas evidencias já foram observadas em um estudo realizado no Maranhão, onde verificou-se que algumas mulheres apresentavam consciência do risco, mas não adotavam medidas preventivas (COSTA et al., 2013). 
Estudos afirmam que a não percepção à vulnerabilidade em contrair uma DST, devido a confiança no parceiro, ao fato de estarem em um relacionamento, onde o mesmo não tem outras parcerias sexuais, poderia ser um fator de vulnerabilidade, pois quando a mulher não se considera em risco não há adoção de comportamentos protetores (OLIVEIRA e SANTOS, 2012; MADUREIRA e TRENTINI, 2008).

A prevenção das doenças sexualmente transmissíveis entre as mulheres depende de sua conscientização sobre a existência do risco. A auto percepção de vulnerabilidade adequada contribuiria para evitar comportamentos e situações de risco, assim como além de adotar rotineiramente o uso do preservativo adotar também outras medidas preventivas (SILVEIRA et al., COSTA et al., 2014; DUARTE et al., 2014).

\section{CONCLUSÃO}

O estudo demonstrou que a percepção das mulheres que realizam visita íntima em unidade prisional em relação vulnerabilidade a contrair uma IST está diretamente ligado ao sentimento de confiança no parceiro e ao fato do mesmo estar encarcerado inviabilizando alguma outra parceria sexual. Por outro lado, o uso do preservativo como método de prevenção foi levantado pelas participantes como fator que as protege, embora, parte da amostra se vê como possível alvo de contaminação e atribui a vulnerabilidade à sujidade encontrada nas celas. O grau de conhecimento das mulheres sobre as IST foi deficiente, pois, as participantes desconheciam, tinham ideias errôneas ou ainda não respondiam com confiança quando indagadas a respeito das formas de transmissão. No que diz respeito à prevenção o conhecimento foi tido como limitado, uma vez que foi citado somente o uso do preservativo. Outro fator claramente observado no estudo foi a gestação ser o motivo que levou a maioria das mulheres a obter informações acerca da temática. Foram levantados como fatores de risco às mulheres em visita íntima a baixa escolaridade, por deterem menor conhecimento quanto às IST; não se sentirem vulneráveis, pois por não se achar em risco não há a tomada de medidas protetoras.

\section{REFERÊNCIAS}

1. ALQUIMIM AF. Comportamento de risco para HIV em população carcerária de montes claros (MG). Rev. Unimontes científica. 2014; 16(1):48-54.

2. CAMARGO BV, JUSTO AM. IRAMUTEQ: um software gratuito para análise de dados textuais. Temas psicol. [Internet]. 2013; 21(2): 513-18.

3. COSTA ACPJ, LINS AG, ARAÚJO MFM et al. Vulnerabilidade de adolescentes escolares às DST/HIV, em Imperatriz - Maranhão. Rev Gaúcha Enferm. 2013; 34(3): 179-86.

4. COSTA FM, MENDES ACF, MARIA DC et al. A percepção feminina quanto à vulnerabilidade de se contrair DST/AIDS. Rev Universidade Vale Rio Verde, 2014; 12(2): 879-89.

5. DUARTE MTC, PARADA CMGL, SOUZA LR. Vulnerability of women living with HIV/aids. Rev Latino-Am Enfermagem. 2014; 22(1): 68-75.

6. FAGEEH WM. Sexual behavior and knowledge of human immunodeficiency virus/aids and sexually transmitted infections among women inmates of Briman Prison, Jeddah, Saudi Arabia. BMC Infect Dis. [Internet]. 2014; 24(14): 290-7.

7. LIMA IMB, OLIVEIRA AEC, ANDRADE JM et al. Modelo de decisão sobre o uso de preservativos: uma regressão logística multinomial. Tempus, actas de saúde colet. 2016; 10(2), 67-80.

8. LOPES AOS, OLIVEIRA CCS. Saúde da mulher em situação de prisão: direitos sexuais e reprodutivos. Rev Saúde Com. 2014; 10(4): 392-408.

9. MADUREIRA VSF, TRENTINI M. Da utilização do preservativo masculino à prevenção de DST/aids. Ciênc. saúde coletiva 2008; 13(6): 1807-16.

10. MALAGON ORA; DINA C. O conceito de vulnerabilidade e seu caráter biossocial. Interface (Botucatu), 2015; $19(53): 237-250$.

11. MATOS MA, CAETANO KAA, FRANÇA DDS et al. Vulnerabilidade às Doenças Sexualmente Transmissíveis em mulheres que comercializam sexo em rota de prostituição e turismo sexual na Região Central do Brasil. Rev Latino-Am Enfermagem. 2013; 21(4): 906-12.

12. MORRIS L, KOUYA F, KWALAR R et al. Factors associated with inconsistent condom use in adolescents with negative or unknown HIV status in Northwest Cameroon. AIDS Care, 2014; 26(11):1440-5. 
13. MOURA DS, PESSOA RMC, ALMEIDA MM. SEXUALIDADE NA TERCEIRA IDADE: uma discussão acerca das medidas de prevenção do hiv/aids. ReonFacema, 2017 Jan-Mar; 3(1):407-415.

14. OLIVEIRA MGF, SANTOS AFPR. Desigualdade de gênero no sistema prisional: considerações acerca das barreiras à realização de visitas e visitas íntimas às mulheres encarceradas. Caderno Espaço Feminino, 2012; 25(1): 236-46.

15. REIS CB, BERNARDES EB. O que acontece atrás das grades: estratégias de prevenção desenvolvidas nas delegacias civis contra HIV/AIDS e outras doenças sexualmente transmissíveis. Ciênc saúde coletiva, 2011 Jul; 16(7): 3331-38.

16. RODRIGUES LSA, PAIVA MS, OLIVEIRA JF et al. Vulnerabilidade de mulheres em união heterossexual estável à infecção pelo HIV/Aids: estudo de representações sociais. Rev Esc Enferm USP, 2012; 46(2):34955.

17. ROSA F, CARNEIRO M, DURO LN et al. Prevalência de anti-HCV em uma população privada de liberdade. Rev Assoc Med Bras., 2012; 58(5):557-60.

18. SALAUDEEN AG, MUSA OI, OJÓTULA A et al. Condom use among people living with HIV/AIDS attending Abejukolo General Hospital in Kogi State, North Central Nigeria. Ann Afr Med., 2014; 13(3):99-103.

19. SAMPAIO J, SANTOS RC, CALLOU JLL et al. Ele não quer com camisinha e eu quero me prevenir: exposição de adolescentes do sexo feminino às DST/aids no semi-árido nordestino. Saude soc., 2011; 20(1): 171-81.

20. SILVA CM, VARGENS OMC. A percepção de mulheres quanto à vulnerabilidade feminina para contrair DST/HIV. Rev esc enferm USP. 2009; 43(2): 401-06.

21. SILVEIRA MF, BÉRIA JU, HORTA BL et al. Autopercepção de vulnerabilidade às doenças sexualmente transmissíveis e Aids em mulheres. Rev Saúde Pública, 2002; 36(6): 670-7.

22. SOUZA ATS, CASTRO AM, FREIRE VS et al. Educação em saúde para prevenção das doenças sexualmente transmissíveis/AIDS no sistema penitenciário. Rev Interd., 2013; 6(4): 142-52. 